\title{
ARTIGOS
}

\section{FEMINISMOS CONTEMPORÂNEOS E INTERSECCIONALIDADE 2.0: \\ UMA CONTEXTUALIZAÇÃO A PARTIR DO PENSAMENTO TRANSFEMINISTA}

\author{
Jaqueline Gomes de Jesus ${ }^{1}$
}

O processo de globalização, acelerado pelas Novas Tecnologias de Informação e Comunicação, tem perpassado fronteiras culturais e propiciado mudanças nas concepções de gênero: tanto nas relações sociais quanto na própria conceituação acerca do que são homens e mulheres. As diferentes vertentes feministas apresentam um papel central nessa transformação, utilizando-se dos recursos da virtualidade para difundir discursos que pressupõe a interação de opressões e a interseccionalidade de identidades como subsídios para a construção de novas práticas sociais. Enquanto novíssimo pensamento-ação feminista, o Transfeminismo incorpora essas características na sua constituição e difusão, constituindo-se como um exemplo das múltiplas aplicações do Feminismo em termos de teoria e política. O presente artigo visa a compor um panorama sintético de discussões contemporâneas do Feminismo, com base na internet, a partir de revisão bibliográfica e da apresentação das concepções de 6 (seis) lideranças transfeministas brasileiras, coletadas via rede social e dispostas na forma de diálogo.

PALAVRAS-CHAVE: Feminismo; Gênero; Cultura; Interseccionalidade; Transfeminismo.

\footnotetext{
${ }^{1}$ Professora de Psicologia do Instituto Federal do Rio de Janeiro (IFRJ). Pesquisadora-Líder do ODARA - Grupo Interdisciplinar de Pesquisa em Cultura, Identidade e Diversidade (CNPq). Doutora em Psicologia Social do Trabalho e das Organizações pela Universidade de Brasília. Pós-Doutora pela Escola Superior de Ciências Sociais da Fundação Getúlio Vargas, Rio de Janeiro.
} 


\section{Introdução}

Os elementos da cultura contemporânea que têm propiciado mudanças nas concepções de gênero têm-se demonstrado alvo de curiosidade popular, por meio de produtos culturais voltadas à temática, como novelas, programas de televisão, peças de teatro, clipes musicais et cetera, e instigantes objetos de estudo em diferentes áreas do conhecimento (GLOBO, 2017).

Como eles transformam nossa concepção, como sociedade, acerca das relações entre homens e mulheres? Ou mais radicalmente, a própria conceituação do ser homem ou mulher?

As novas concepções sobre gênero se configuram, em um estágio inicial, como micro revoluções, cada vez mais perceptíveis, integradas ao processo de globalização e as Novas Tecnologias de Informação e Comunicação, que afetam a constituição subjetiva de indivíduos e grupos sociais no sentido de uma reavaliação de valores e práticas (JESUS, 2013a).

Um exemplo, em nível internacional, é o sucesso da cantora Teca Miguel Garcia, conhecida como Titica, considerada a Rainha do Kuduro ${ }^{2}$ em Angola. Ela tem ocupado um lugar de destaque na divulgação da cultura angolana, apesar de tantos preconceitos que a cercam e de discriminações que lhe são impingidas por ser uma mulher trans no cenário cultural da África (PRADO, 2017).

A internet tem sido um campo prolífico para a divulgação de suas músicas e de seus videoclipes, que não se limitam à sua terra natal, mas avançam pelo mundo, principalmente pelo repositório de vídeos Youtube, o qual tem sido apropriado por diferentes produtores de conteúdo e formadores de opinião, tanto os que rediscutem o status quo quanto os que idealizam a retomada de um status quo ante no qual a diversidade de gênero e sexual era invisibilizada.

Questionamentos e revoltas aqui e ali, provocados pelos feminismos contemporâneos, eventualmente vistos nas ruas, nascem na internet, nas redes sociais, no mundo virtual, frutificando no mundo físico e transformando a realidade.

A emergência das identidades trans, em uma conjuntura global de visibilidade cada vez mais positiva, é um aspecto central do cenário de ressignificação do gênero e da consolidação do conceito de identidade de gênero,

\footnotetext{
${ }^{2} \mathrm{O}$ Kuduro é um gênero musical e de dança originário de Angola, nascido nos fins dos anos 80 do século XX, influenciado pelo rap. O termo se refere, literalmente, à "bunda dura" dos seus intérpretes. O ritmo se popularizou entre países de língua portuguesa, tendo-se tornado mais conhecido pela exposição de kuduristas (dançarinos de Kuduro) na periferia de Paris (ver https://en.wikipedia.org/wiki/Kuduro).
} 
entendido como a "atitude individual frente aos construtos sociais de gênero, ante aos quais as pessoas se identificam como homens ou mulheres" (JESUS, 2014a, p. 246).

O presente artigo visa a compor um panorama sintético de discussões contemporâneas do Feminismo, com base na internet, a partir de revisão bibliográfica e da apresentação das concepções de 6 (seis) lideranças transfeministas brasileiras, coletadas via rede social e dispostas na forma de diálogo.

\section{Feminismos, interseccionalidade e gênero}

Esses feminismos praticam, em suas vertentes mais populares, uma interseccionalidade digital que pode ser denominada como $2.0^{3}$ : na qual o discurso acerca da interação de opressões e da indissociabilidade das identidades, oriundo do Feminismo Negro (JESUS, 2014a), vai além do oral e encontra o escrito e o imagético na rede global de comunicação.

As nossas imagens sobre quem são as mulheres - e os homens - têm sido afetadas pelas mensagens que circulam pelas redes sociais, pelos blogs, pelos micro blogs e por outros programas informatizados.

Mudanças definem a História da Humanidade, mas o que vemos hoje é uma aceleração do processo, com a desfragmentação de fronteiras culturais, decorrente do aprimoramento tecnológico dos meios de comunicação. Cabe lembrar que nem sempre os estereótipos de gênero foram esses com os quais convivemos, pautados prioritariamente pelo binarismo homem-mulher.

No século XVI europeu, por exemplo, a mulher não era considerada um ser completo, um gênero por si. Era, sobretudo, um "homem incompleto", cujo órgão genital não conseguiu sair do corpo para se tornar um pênis.

É antiga a noção de que haveria uma diferença essencial entre homens e mulheres pautada pelos seus sexos biológicos, geralmente definidos, leigamente, a partir da observação dos órgãos genitais. Essa percepção, porém, modificou-se ao longo do tempo e das culturas.

A concepção de que há dois sexos diferentes surgiu no século XVIII. Anteriormente prevalecia o monismo sexual: a ideia de que há um único sexo. Em registros datados do século II, nos tratados de Galeno, afirma-se que o sexo feminino

\footnotetext{
${ }^{3} \mathrm{O}$ "2.0" é uma referência às atualizações de softwares que recebem números em função de novas versões. Neste caso, foi utilizado o 2 , ao invés de 1.2 , por exemplo, porque não considero os Feminismos de internet, incluindo o Transfeminismo, como meros acréscimos ou correções pontuais aos Feminismos Interseccionais que lhes antecederam, mas, isso sim, reelaborações dos conceitos e práticas daqueles, contextualizadas à Sociedade do Conhecimento e suas tecnologias.
} 
era um subdesenvolvimento do sexo masculino - o órgão genital feminino (vagina) seria um órgão genital masculino (pênis) incompleto - ou seja, entendia-se que mulheres eram homens imperfeitos (LAQUER, 2001).

$\mathrm{O}$ conceito de gênero existe no meio científico desde meados do século XX. Ele surgiu a partir das considerações de Money (1955) acerca dos papéis construídos socialmente para homens e mulheres, e apontou o gênero como uma categoria referente ao conjunto de características que definem diferenças sociais entre homens e mulheres.

Dessa forma, ele diferenciou esse conceito de sexo biológico, evidenciando que nem sempre as expectativas sociais relacionadas às pessoas nascidas com determinadas configurações biológicas (femininas ou masculinas) redundarão na identificação com certo gênero (homem ou mulher). A mesma conclusão apresenta Bento $(2006,2008)$ em seus estudos sobre a vivência transexual.

As sociedades contemporâneas, de forma geral, ante às anatomias genitais tradicionalmente entendidas como feminina (vagina) ou masculina (pênis), costumam generalizar suas concepções de mundo com base na crença de que o sexo seja algo universal (todos os seres vivos teriam sexo), binário (macho e fêmea) e globalizante das identidades e dos papéis sociais. Essa crença se mostra falaciosa quando consideradas as vivências de diferentes povos e grupos sociais (HERDT, 1996).

A ciência biológica, segundo Roughgarden (2005), considera que somente algumas espécies animais (sexo não é universal) dividem-se em duas ou mais categorias complementares (sexo não é necessariamente binário), denominadas "sexos", que podem combinar o seu material genético para reprodução. Ser fêmea ou macho em uma espécie pode significar papéis totalmente inversos em outras.

Gênero é aqui entendido como "um construto psicossocial significativo [...] que abrange desde crenças e ações individuais até o impacto de sistemas sociais." (DEAUX; LAFRANCE, 1998, p. 788).

Conforme apontam Louro (1998, 2000), Oliveira (1998) e Scott (citada em GROSSI; HEILBORN; RIAL, 1998), o conceito de gênero é relacional e político independendo das bases biológicas como o sexo - e determina, entre os seres humanos, papéis que eles exercem na sociedade - o que de forma alguma se restringe à sexualidade.

O conceito de gênero foi incorporado ao Feminismo e à produção acadêmica sobre mulheres nos anos 1970 e, desde então, tem sido interpretado de formas distintas por diferentes correntes do Feminismo. 
Segundo Carvalho (1998), o uso ainda hoje mais frequente do conceito de gênero é o proposto pelo Feminismo da diferença. Esse conceito rejeitou pressupostos do Feminismo da igualdade, que afirma que as únicas diferenças efetivamente existentes entre homens e mulheres são biológico-sexuais e que as demais diferenças observáveis são culturais, derivadas de relações de opressão, portanto, devem ser eliminadas para dar lugar a relações entre seres "iguais".

Para as teóricas e os teóricos da diferença, o conceito de gênero remete a traços culturais femininos (ou, no polo oposto, masculinos) estruturados socialmente sobre a base biológica. Constrói-se, assim, uma polarização binária entre os gêneros, na qual a diferença é concebida como categoria central de análise, fundamental na definição de estratégias de ação (HITA, 1998). As diferenças entre homens e mulheres são enfatizadas estabelecendo-se uma polaridade entre masculino e feminino, produção e reprodução, público e privado.

A vertente pós-estruturalista do Feminismo, por sua vez, destaca o caráter histórico das diferenças entre os gêneros e a própria construção social da percepção da diferença sexual (SCOTT, 1995). Essa corrente chama a atenção, sobretudo, para a necessidade de se romper com a homogeneização interna a cada um destes campos: o feminino e o masculino, reconhecendo a existência de diversidade no interior de cada um - o que requer que se incorpore à análise outras dimensões das relações sociais, tais como raça, classe e geração (NICHOLSON, 1994).

Quando alguém se veste está fazendo uso de uma linguagem não verbal que comunica, conscientemente ou não, seus marcadores sociais: status, profissão, gênero e outros. O corpo é o anteparo da vestimenta. Isso não significa que essa relação é a de uma mera soma de elementos. A roupa não está apenas sobre o corpo, ela se incorpora ao corpo, faz parte dele, acentuando ou mascarando sinais.

As explicações sobre o corpo calcadas no modelo anatômico-biológico não são suficientes para abarcar as dimensões culturais e simbólicas das práticas e dos usos dos corpos (MAUSS, 2011).

No que se refere às questões de gênero, os corpos se tornam elementos de patente importância na auto-identificação e na hétero-identificação dos indivíduos: mulheres se vestem assim, homens se vestem assado; estereótipos; marcas fixas no ideário sobre os corpos que adquirem um juízo de valor. Há mulheres e homens considerados melhores ou piores em função da beleza atribuída ao que vestem, aos usos que fazem de seus corpos. 
Para as mulheres, principalmente, o embelezamento é uma prática historicamente associada à feminilização (SANT'ANNA, 2003). A aparência das mulheres se torna um elemento central na sua identificação social e até mesmo na sua autoestima - mais do que para homens.

Os meios midiáticos, como processos comunicacionais baseados em práticas e discursos sociais, produzem subjetividades fundamentadas na difusão de signos de toda espécie, gerando comportamentos e fortalecendo ou enfraquecendo ideologias.

No campo das discussões sobre gênero, enquadram-se as tecnologias do gênero mencionadas por Lauretis (1994), as quais produzem, promovem e implantam representações sobre masculinidades e feminilidades.

Os corpos femininos são mercantilizados, especialmente em propagandas, mas não somente nelas, por meio da divulgação de determinadas imagens, em contextos nos quais são tratados como bônus para o possível consumidor, na aquisição de um produto relacionado àquelas imagens.

Não todo corpo, mas alguns corpos. Quais? Quem assiste ou lê qualquer mídia audiovisual ou impressa e está minimamente atento(a) sabe que, geralmente, há corpos privilegiados: brancos ou pálidos, magros ou esquálidos, e até mesmo voluptuosos. Nenhum meio-termo.

São corpos marcados como "melhores", ou até mesmo, popularmente, como corpos de "mulheres de verdade", na tradição das Amélias. A título de exemplo, em 2010, a revista norte-americana Fitness Magazine conferiu à filha do roqueiro Ozzy Osbourne o título de "Melhor Corpo de 2010". Para isso, ela tinha perdido 20 quilos para participar de um reality show.

Esses corpos são inatingíveis à maioria das mulheres, cujos perfis anatômicos, étnicos ou mesmo as preferências estéticas não coincidem com eles. Modelos excludentes, cuja afirmação pelos meios de comunicação carrega preconceitos acerca da diversidade do que é ser feminina, fundados em julgamentos morais para escarnecer, admoestar ou negar outros corpos.

Entre as manchetes de revistas que prometem emagrecimento imediato por meio de dietas mirabolantes ou de tratamentos cirúrgicos, propagandeados como se qualquer cirurgia fosse um procedimento sem riscos, pululam exemplos edificantes de personalidades com mais de 40 anos de idade, porém "com corpinho de 20", ou que, em pouco tempo, emagreceram muito. 
Prepondera o argumento de que esses corpos são saudáveis, entretanto, tais mensagens podem ser benéficas para as jovens e adultas que compõem o públicoalvo das publicações?

Mais do que apenas um culto ao corpo, essa é uma tentativa de negar a possibilidade do corpo feminino se expressar em diferentes moldes.

Os comerciais de cerveja são conhecidos pela associação de elementos machistas que, além de inferiorizarem o papel das mulheres na sociedade, representam-nas de forma depreciativa, como pessoas passivas, cujos corpos podem ser facilmente explorados, porque são tratados apenas como objetos eróticos. São representações do feminino a serviço do desejo masculino, nas quais a figura feminina, alienada do próprio desejo e do controle sobre o seu corpo, permanece, no dizer de Funck (2002, p. 1), “aprisionada em papéis dicotômicos de amante submissa ou de perigosa devoradora de homens".

Em vez de se tornar campo de experienciação da individualidade de cada mulher, o corpo feminino é retratado como propriedade de um outro, geralmente um outro com olhar sexista sobre esse corpo.

Corpos atestados como maus. Isso remete a um tempo em que já foi normal falar que os cabelos crespos das pessoas negras eram "ruins". A questão veio à tona em artigo publicado no jornal $O$ Globo, quando o jornalista e escritor Zuenir Ventura comentou em relação à entrevista dada pelo então jogador de futebol Ronaldo Fenômeno ao Fantástico sobre o recente "escândalo" envolvendo travestis e extorsão ${ }^{4}$.

Nesse artigo, denominado "A Falha do Ronaldo", Ventura critica o cabelo do jogador: "Acho que fez bem em ir à televisão, embora devesse ter raspado a cabeça. Aquele cabelo bombril parecendo tingido me fez entender o que ele disse uma vez, causando polêmica - que tinha 'cabelo ruim'.” (VENTURA, 2008, p. 7). Apesar de não envolver repúdio à estética de uma mulher, isso mostra como o controle sobre os corpos de populações discriminadas é ostensivo neste país, inclusive nos meios de comunicação.

Em 16 de setembro de 2011, o site Vírgula, pertencente ao UOL, listou personalidades que tiveram um dia de cabelo ruim, alcunhado "Bad hair day", entre

\footnotetext{
${ }^{4}$ As discussões no caso da extorsão não priorizaram o fato de o jogador ter traído a noiva, mas de supostamente manter relações com travestis. O debate retrata o nível acentuado de estigmatização a que são submetidas as travestis, em que o relacionamento afetivo com elas é tido como abjeto. Uma perversa lógica estigmatizante que, ao tomar as travestis como seres abjetos, atribui-lhes um caráter infecioso, de "contaminação".
} 
as quais consta a atriz Whoopi Goldberg com tranças afro simples, utilizadas por muitas mulheres negras. Sob a foto da artista, uma juízo estético-moral: “assuma o black power, gata! Essas trancinhas são realmente feias". Posteriormente, o comentário foi retirado.

A submissão das estéticas negras a outras estéticas é parte de um debate antigo e estigmatizador que tem trazido sofrimento a gerações de mulheres e homens negros brasileiros, cujos corpos são negados desde o período colonial.

$\mathrm{Na}$ contemporaneidade, em que a identidade negra é rediscutida e valorizada, tal histórico gera uma zona de tensão. No entendimento de Gomes (2002), a identificação do cabelo das pessoas negras como "ruim" é uma expressão da desigualdade racial que tende a dominar a população afro-brasileira.

É praxe das mídias menos atentas à pluralidade do feminino reforçar estereótipos sobre o que é ou não ser mulher. As referências visíveis de mulher tendem a remeter apenas às brancas, abastadas e magras, ignorando que há as negras, indígenas, gordas, lésbicas, pobres, transexuais. Nessa última dimensão, na qual se demonstra que nem a biologia nem a anatomia determinam o que é uma mulher, o peso de uma suposta "verdade" prepondera e discrimina.

No dia 18 de janeiro de 2011, outra participante de reality show foi eliminada. Não seria nada demais na rotina desse tipo de programa, se não fosse pela rejeição do público estar calcada em um preconceito.

O jornalista Neto Lucon (2011) argumentou na revista A Capa que a participante Ariadna incomodava porque existia: ela é uma mulher transexual, que não se preocupou em informar isso aos demais concorrentes do claustro televisionado. Entretanto, o fato foi noticiado pelos meios de comunicação, e a omissão dela foi "malvista" por alguns telespectadores.

Por que o público achava que ela deveria anunciar sua condição de gênero, um aspecto puramente íntimo? Porque desqualificava sua identidade como mulher prática extremamente danosa à identidade de qualquer uma, biológica ou não. Essa é uma das características da transfobia (JESUS, 2015).

Ainda perdura em nossa sociedade uma percepção sexista - oriunda de uma visão limitante sobre o ser humano, porém reproduzida acriticamente em boa parte das mídias - de que algumas pessoas são legítimas, outras não. Dentre estas são enquadradas as pessoas trans. Essa preconcepção não é inócua e tem estimulado a negação de vários corpos e, consequentemente, uma negação de humanidade. E no caso em particular das mulheres trans, uma desvalorização de sua "mulheridade", da 
sua condição de mulher, como se fossem menos mulheres do que as cisgêneras/cis (que não são transgêneras/trans) ${ }^{5}$.

Podemos falar de uma pluralidade semiótica do Feminismo. Não há uma corrente teórica única do pensamento feminista. Pode-se falar de "feminismos", porque existem correntes teóricas diversas que, apropriadas com base em teorias gerais, procuram, a seu modo, compreender por que e como as mulheres ocupam uma posição/condição subordinada na sociedade.

O Feminismo, na prática, é um bloco de correntes heterogêneas que tenta explicar as condições de subordinação das mulheres, tendo como bases comuns:

a) o reconhecimento de uma causa social e cultural para essas condições;

b) a incorporação da necessidade de uma tomada de consciência individual e coletiva contra tais condições;

c) uma revolta contra o entendimento presente nas relações de gênero em uma dada sociedade e em um dado momento da história.

O Feminismo, em suas múltiplas expressões, é uma luta para mudar/transformar essas relações e essa situação (BANDEIRA, 2008).

O Feminismo, dito assim, no singular, foi definido como "uma das formas tomadas pelo individualismo moderno" (FRANCHETTO; CAVALCANTI; HEILBORN, 1980, p. 32), fundamentado na compreensão das mulheres como indivíduos que passam a questionar os papéis sociais determinados por diferenças de gênero, mais comumente chamadas de diferenças sexuais, que são pautados pela dominância social de homens sobre mulheres e pela restrição das mulheres ao espaço privado.

Logo, o Feminismo, entendido como um movimento social moderno, surge como mobilização contra a inferiorização das mulheres com base em alegadas diferenças biológicas (geralmente relacionadas à capacidade reprodutiva), que se tornam estigmas de um destino naturalizado, e a favor da ocupação de espaços públicos, então reservados apenas aos homens.

No final da década de 1970, começa o debate "igualdade-versus-diferença" (PIERUCCI, 1990). Igualdade, diferença, cultura e natureza são compreendidas como categorias que se intercruzam e tornam conflituoso e polissêmico o debate feminista (KOFES, 1993).

\footnotetext{
${ }^{5}$ Ver Jesus (2012).
} 
No entanto, com o advento das teorias pós-modernas, as oposições binárias (homem x mulher, igualdade x diferença, natureza x cultura) se demonstram frágeis como categorias e começam a ser desconstruídas por não encerrarem em si mesmas nenhum significado último ou fixo. Dessa forma, são consideradas vazias e transbordantes, uma vez que mascaram a heterogeneidade de cada categoria e as diferenças internas de cada polo da oposição, numa relação hierárquica entre duas categorias (SCOTT, 1988).

\section{Feminismos e internet}

Como espaços alternativos de sociabilidade, as redes digitais têm possibilitado a propagação, com menos intermediários e para uma audiência relativamente grande, de contradiscursos acerca de regras estabelecidas de comportamento e de modelos fixos de identidade. Contradiscursos que reafirmam os aspectos mais inclusivos dos feminismos interseccionais.

Alguns sites de cunho feminista, como a Universidade Livre Feminista ${ }^{6}$; o Blogueiras Feministas ${ }^{7}$; o Blogueiras Negras ${ }^{8}$; a Revista AzMina ${ }^{9}$, o Transfeminismo ${ }^{10}$, focado na realidade e nos desafios das pessoas trans; e o Geledés Instituto da Mulher Negra ${ }^{11}$, com enfoque aprofundado nos aspectos étnico-raciais, entre outros, têm disseminado uma série de artigos e opiniões questionando a legitimidade do discurso monotemático sobre feminilidades, o qual outrora se restringia ao mundo acadêmico. Nesses sites, cultura, mídia, política, relacionamentos, saúde, trabalho e violência são temas ressaltados que posicionam as mulheres como protagonistas digitais e as estimulam a se tornarem atores sociais no mundo físico.

No âmbito das mídias que utilizam esse recurso, vale citar a coluna Mulher 7x7, da revista Época, na qual sete colaboradoras suavizam o tom adotado pelos sites supracitados, empregando um discurso intermediário de independência, para tratar de ideários de saúde, moda e beleza no cotidiano de mulheres.

Nessa publicação, excetuando-se receituários sobre comportamento corporativo idealizado ou relatos afetivo-sexuais, encontrados em quaisquer outras mídias voltadas ao público feminino, podem ser destacadas matérias contendo sérias

${ }^{6} \mathrm{http} / / / \mathrm{www}$. feminismo.org.br/livre

${ }^{7}$ http://blogueirasfeministas.com

8 http://blogueirasnegras.org

9 http://azmina.com.br

${ }^{10} \mathrm{http}: / /$ Transfeminismo.com

11 http://www.geledes.org.br 
discussões contemporâneas, como "É hora de queimar sutiãs para valer?" (BUSCATO, 2010), sobre o livro "Enlightened Sexism”, da pesquisadora de gênero Susan Douglas, o qual denuncia a camuflagem do sexismo moderno, que não se assume como tal e reitera, nos meios de comunicação, imagens de mulheres poderosas e bem-sucedidas, porém ignora o fato de que ainda não há igualdade entre homens e mulheres, ao mesmo tempo em que exige que as mulheres sempre se superem.

No universo virtual, além dos websites, destacam-se os blogs, nos quais os indivíduos podem publicizar seus pensamentos a um público maior do que em outros contextos, por meio de postagens, sem compromissos laborais ou linhas políticas fixas.

O micro blog Twitter, estimulando a postagem de mensagens curtas com até 120 caracteres (tweets), abriu um campo extraordinário para difusão de opiniões e tem sido utilizado por parte considerável dos meios de comunicação e por diversos comentaristas para difusão rápida e imediata de notícias, contatando diretamente os leitores virtuais.

A filóloga cubana Yoani Sánchez, utilizando-se do Twitter e de seu blog Generación $Y^{12}$ para retratar o cotidiano e a política de seu país, destacou-se internacionalmente como fonte, tendo sido indicada pela revista Time como uma das 100 pessoas mais influentes do mundo em 2008 (HIJUELOS, 2009, p. 31).

A blogueira não se omite na discussão sobre o papel das mulheres em sua sociedade, criticando desde o tradicionalismo da Federación de Mujeres Cubanas (FMC) até o mercado de compra e venda de cabelos, capital de muitas mulheres no país, segundo Sánchez, que os vendem quando estão em situação financeira difícil.

O texto "Orgulho de ser gordinha" (ASSIS; FERRAZ, 2011), no Blog das $\operatorname{Garotas}^{13}$, comenta o orgulho que elas têm de serem "gordinhas" e defendem que ser assim não pode mais ser visto como um defeito. O teor carinhoso nos discursos acerca da obesidade, patente na adoção do diminutivo, tem-se tornado comum nas redes sociais, a exemplo da comunidade Gordinhos e Gordinhas ${ }^{14}$ do site de relacionamentos Facebook.

\footnotetext{
12 http://www.desdecuba.com/generaciony

${ }_{13} \mathrm{http}: / /$ laybdg.blogspot.com.br

${ }^{14} \mathrm{http}: / /$ www.facebook.com/pages/Gordinhos-e-Gordinhas/140733359351167?sk=info
} 
Na mesma rede social, a comunidade Mulher Negra Consome ${ }^{15}$ propõe uma discussão sobre o direito das mulheres negras de serem melhor retratadas no campo da estética comercial e midiática, reclamando por marcas e produtos voltados a elas, hoje escassos, e criticando a falta de modelos negras em editoriais de moda e na publicidade. A comunidade também disponibiliza espaço para denúncias e protestos contra o sexismo e o racismo.

O grupo aberto Feministas e Feminismo em ativismo digital ${ }^{16}$ é característico da remodelagem de conceitos sobre relações de gênero propiciada pelas mídias e redes sociais. Atualmente com 496 membros, promove ativismo online em prol do fim da violência contra as mulheres.

As blogueiras e ativistas transfeministas Daniela Andrade, Sofia Ricardo Fávero e Helena Vieira, entre outras, destacaram-se, em diferentes momentos, por suas considerações e seus posicionamentos críticos acerca do sexismo e da transfobia que violam as identidades e os direitos da população trans, por meio de postagens em diversos meios internéticos e, respectivamente, do blog Alegria Falhada ${ }^{17}$, da comunidade Travesti Reflexiva $^{18}$, da Revista Fórum ${ }^{19}$ e da página Huffpost Brasil ${ }^{20}$, todas com reflexões postadas no Facebook.

\section{Diálogo Transfeminista}

Conforme apontado em publicações anteriores, o Transfeminismo é uma linha de pensamento e ação feminista em construção, na prática uma literatura de fronteira (Jesus, 2014b), fortemente baseada na internet e herdeira, principalmente, das contribuições teórico-práticas do Feminismo negro, no que concerne ao princípio da interseccionalidade, à não-hierarquia de opressões, ao empoderamento das falas das pessoas historicamente oprimidas e ao questionamento da apropriação do conceito de mulher pelas feministas brancas, que:

surge como uma crítica ao cissexismo ou dimorfismo ${ }^{21}$ e à falha do Feminismo de base biológica em reconhecer plenamente o gênero como uma categoria distinta da de sexo e mais

\footnotetext{
${ }^{15}$ http://www.facebook.com/groups/mulhernegraconsome

${ }^{16}$ http://www.facebook.com/groups/176594019024578

${ }^{17} \mathrm{http}: / / \mathrm{www}$.alegriafalhada.com.br

${ }^{18} \mathrm{http}: / /$ www.facebook.com/TReflexiva

${ }^{19} \mathrm{http}: / /$ www.revistaforum.com.br

${ }^{20} \mathrm{http} / / /$ www.huffpostbrasil.com

${ }^{21}$ Crença na divisão binária dos gêneros, em suposta concordância com os sexos biológicos feminino e masculino.
} 
importante do que esta para o entendimento dos corpos e das relações sociais entre homens e mulheres (JESUS e ALVES, 2010, p. 14).

não pode ser entendido como único, porém, de forma genérica, pode-se entender que há princípios sem os quais uma determinada linha de pensamento do Feminismo não pode ser considerado transfeminista:

1. redefinição da equiparação entre gênero e biologia;

2. reiteração do caráter interacional das opressões;

3. reconhecimento da história de lutas das travestis e das mulheres transexuais e das experiências pessoais da população transgênero de forma geral como elementos fundamentais para o entendimento do Feminismo;

4. validação das contribuições de quaisquer pessoas, sejam elas transgênero ou cisgênero, o que leva ao fato de que, por sua constituição, o Transfeminismo pode ser útil para qualquer pessoa que não se enquadra no modelo sexista ${ }^{22}$ de sociedade que vivemos, não apenas às transgênero (JESUS, 2014b, p. 249).

A fim de apresentar um painel simplificado, que abarque algumas das vozes da atualidade que têm promovido debates transfeministas no Brasil, foi realizado um debate via rede social Facebook, entre 17 e 31 de outubro de 2015, no qual foram apresentadas as 6 (seis) lideranças trans brasileiras que se reconhecem como transfeministas, questões relacionadas ao movimento em si e a como eles percebem o seu relacionamento com outras iniciativas da sociedade civil.

Participaram 4 (quatro) mulheres trans: BPB, VV, DA e VG; e 2 (dois) homens trans: LP e ALGO.

A proposta foi a de tratar, da maneira mais informal possível, antecedentes teóricos e o pensamento trans no universo feminista atual (questionamentos, perspectivas e proposições/contribuições teórico-críticas).

Abaixo são transcritas as conversações efetuadas:

Pesquisadora: Quando você começou a ter contato com o Transfeminismo?

BPB: Eu tive contato pela primeira vez por volta de 2011 e 2012, os grupos de Facebook e os contatos na rede foram essenciais.

ALGO: Meu primeiro contato também foi pelo face[book], num grupo de Transfeminismo, acho que em 2012.

VG: Em 2013, pelo Facebook também.

\footnotetext{
${ }^{22} \mathrm{O}$ sexismo pode ser entendido como uma forma de apartheid com consequências psicossociais e institucionais negativas, especialmente no que concerne ao direito à autodeterminação das pessoas (ROTHBLATT, 1995).

Sexismo, "na definição de McArthur e McArthur (1998) se refere à crença de que homens, como representantes do sexo masculino, são o padrão 'normal' da sociedade, o que incorre na suposição de que mulheres, como pessoas do sexo feminino, seriam inferiores e subordinadas aos homens. O que está em jogo, no caso do sexocentrismo/sexismo, segundo Foucault (1985), é o posto que o sexo biológico masculino ocupa na sociedade como 'sexo-rei', com relação ao sexo biológico feminino" (Jesus, 2013b, p. 365).
} 
VV: Oi, gente! Deixe pensar... com os Transfeminismos em si, creio que foi de 2012 para 2013, se não me engano, que se iniciaram meus contatos. Com questões trans, foi um pouco antes, a partir da leitura do Whipping Girl, da Julia Serano ${ }^{23}$, por exemplo.

Pesquisadora: Para você, o que é Transfeminismo?

BPB: Eita... pergunta um pouco difícil (risos). Para mim, Transfeminismo é um feminismo que trata das especificidades das pessoas trans. Um feminismo que reconheça a legitimidade do gênero das pessoas trans. O Transfeminismo interroga certos silêncios do Feminismo no que tange a questão trans, mas não é irreconciliável com ele, como algumas feministas radicais postulam.

VV: Vou na mesma toada da B[PB]. Penso [os] Transfeminismos como uma gama de perspectivas feministas, que tem o vetor interseccional "identidades de gênero" como fundamental nas análises. E, neste sentido, interroga os feminismos pelos silêncios que $\mathrm{B}[\mathrm{PB}]$ menciona.

Por outro lado, acho que é importante salientar os aprendizados com os feminismos para complexificar e melhorar as lutas no âmbito LGBT ${ }^{24} \mathrm{e}$ [especificamente] trans. É um esforço que tenho notado nas perspectivas transfeministas.

LP: Oi, pessoal, desculpem o atraso aqui. Vamos lá.

$1^{a}$ resposta (à pergunta inicial "Quando você começou a ter contato com o Transfeminismo?"): Tive contato com o Transfeminismo com o Jamal [Panda] ${ }^{25}$, pela primeira vez, quando ele me fez entender que homens trans também poderiam discutir Transfeminismo. Acho que foi por volta de 2013.

Atualmente, no IBRAT, temos um grupo chamado "construindo o Transfeminismo para as transmasculinidades", é sempre um debate muito difícil porque, além de falar sobre o machismo que sofremos, também precisamos, de forma muito sincera e honesta, pensar sobre o machismo que reproduzimos, muitas vezes também resultante de um processo violento de opressão, mas que precisa ser desconstruído através do empoderamento.

\footnotetext{
${ }^{23}$ O livro da bióloga e escritora trans Julia Serano (2007) demonstra, partindo de suas experiências pessoais, como o preconceito e a discriminação contra as pessoas trans, denominados coletivamente como "transfobia", estão fundamentados no sexismo, de modo que a luta pela emancipação das pessoas trans é, fundamentalmente, feminista.

${ }^{24}$ Sigla para Lésbicas, Gays, Bissexuais, Travestis e Transexuais.

${ }^{25}$ Ativista transfeminista que integra o Instituto Brasileiro de Transmasculinidades (IBRAT).
} 
$2^{a}$ resposta: O Transfeminismo, para mim, é uma das principais ferramentas para a luta trans que, tanto nas transfeminilidades e transmasculinidades, é tangida pelo machismo, grande patologia social que oprime e silencia a livre expressão de gênero.

O Transfeminismo veio para libertar pessoas, sejam elas trans ou não. É uma ideologia, uma prática e uma teoria interseccional que compreende a luta do Feminismo muito além do que a princípio ela poderia projetar. O Transfeminismo nos ajuda a lutar contra o machismo e a transfobia, se tornando uma arma potente para desconstruir os feminismos transfóbicos que negam as identidades de gênero das pessoas trans.

Observação: gostaria de fazer um adendo, de que fico com o cu na mão discutindo Transfeminismo com pessoas tão fodas, que admiro muito aqui, nessa conversa. Obrigado, de nada.

DA: Tive contato com Transfeminismo por volta do ano de 2012. Transfeminismo, para mim, é um movimento social que luta pelo empoderamento das pessoas oprimidas em função do seu gênero, luta pela libertação de pessoas traduzidas como abjetas dentro da sociedade machista e patriarcal, configurada, em todos aspectos, como retificadora do status quo do homem cisgênero.

Pesquisadora: Vamos para a $3^{\mathrm{a}}$ pergunta - O que você acha que o Transfeminismo aprende de outras correntes feministas? E o que ele ensina a elas?

BPB: Bom, vamos lá. Alguém tem que começar (risos).

$\mathrm{Eu}$ acho que o Transfeminismo "aprendeu" — digamos assim — do Feminismo todo um histórico de luta por direitos. Quer dizer, se o Feminismo significou ganhos por direitos ao longo da história, o Transfeminismo pode se basear neste percurso para pensar sobre suas próprias especificidades (direitos, a serem alcançados, das pessoas trans). E acho que vale apontar que os direitos não são autoevidentes, a própria militância constrói historicamente a luta e os próprios direitos que ela reivindica.

VV: Acredito que os Transfeminismos aprendem de outras correntes feministas, em particular, novas formas de diálogo institucional (para além do âmbito LGBT) e, como disse a B[PB], todo um histórico de lutas.

Isso se reflete como aprendizado de (1) estratégias e táticas políticas dentro e fora da institucionalidade e de (2) conceitos e perspectivas teóricas que vêm de feminismos (os negros e não heterossexuais, especialmente), como a interseccionalidade e a construção política dos gêneros. 
Por sua vez, creio que uma das grandes contribuições dos Transfeminismos se refere à colocação em pauta das identidades de gênero e diversidades corporais, desestabilizando fundamentos políticos históricos que constituíram as lutas feministas (o sujeito mulher universalizado).

Nisso, os Transfeminismos se aliam a outras perspectivas feministas das diferenças com o enfoque de identidades de gênero como vetor interseccional. Também acho que os ativismos trans trazem contribuições sobre práticas políticas e modos de vida (desde linguagens de resistência como o pajubá ${ }^{26}$ à sobrevivência contra cissexismos ${ }^{27}$ ) que são de importante incorporação e diálogo nos feminismos.

Pesquisadora: O Transfeminismo tem encontrado adesões no movimento LGBT e no Feminista?

BPB: Hum. É difícil responder essa quarta pergunta.

Eu vejo que existem tanto adesões quanto resistências à entrada do Transfeminismo (ou das ideias e pautas transfeministas) no movimento consolidado de até então.

Eu procuro ser otimista, é claro, [prefiro] pensar que o Transfeminismo tem o potencial de alargar o escopo de luta por direitos do movimento LGBT. Não acho que seja inconciliável o Transfeminismo com os outros movimentos, ao contrário, eu acredito na possibilidade de crescimento do movimento pelo Transfeminismo.

Acho que como o Transfeminismo ainda é relativamente pequeno, as adesões ainda são um pouco limitadas, mas eu vejo que a cada dia estão aumentando. Vejo muito potencial.

\section{Considerações finais}

Seria exaustivo enumerar os milhares de narrativas, senão milhões, que se têm propagado nas redes sociais. A temporalidade imediata do mundo virtual e sua capacidade de gerar espaços para que mais autores possam tornar seus textos públicos são recursos estratégicos para a consolidação de uma democracia efetiva, na qual

\footnotetext{
26 Também conhecida como bajubá, é uma linguagem popular construída de palavras de diferentes línguas africanas, em especial o Iorubá, utilizadas com frequência por adeptos das religiões de matriz afro-brasileira e travestis. Ver Vergueiro (2014).

${ }^{27}$ Preconceitos e discriminação sistêmicos, contra pessoas trans, que reiteram a cisgeneridade (caráter da pessoa cisgênera) como um padrão universal que deve ser seguido. Ver Jesus (2012).
} 
pode ser conhecida a pluralidade de vozes e imagens de e sobre mulheres, todas as mulheres.

A interseccionalidade 2.0 é uma realidade inescapável para os feminismos que pretendem sobreviver no mundo contemporâneo.

Como uma questão de posicionalidade tipicamente feminista, para concluir esta reflexão destaco que, até mesmo em minhas produções acadêmicas, a divulgação científica pelos meios de comunicação virtuais é imprescindível para a popularização de reflexões e pesquisas.

Também a pesquisadora que escreve este artigo científico, de viés nãomasculinista, vive na hiper-realidade em interação com os atores sociais no mundo físico: “Agora, voltemos nossos olhares para a vida" (JESUS, 2014c, p. 111).

\section{Referências Bibliográficas}

ASSIS, L.; FERRAZ, Y. Orgulho de ser gordinha. Blog das Garotas. 24 out. 2011. Disponível em: http://laybdg.blogspot.com.br/2011/10/orgulho-de-ser-gordinha.html

BANDEIRA, L. A contribuição da crítica feminista à ciência feminista à ciência. Estudos Feministas, v. 16, n. 1, p. 207-228, 2008.

BENTO, B. A reinvenção do corpo: sexualidade e gênero na experiência transexual. Rio de Janeiro: Garamond, 2006.

BENTO, B. O que é transexualidade. São Paulo: Brasiliense, 2008.

BUSCATO, M. É hora de queimar sutiãs para valer? Mulher 7x7, 22 abr. 2010. Disponível em: http://colunas.revistaepoca.globo.com/mulher7por7/2010/04/22/ehora-de-queimar-sutias-para-valer

CARVALHO, M. P. Gênero e trabalho docente: em busca de um referencial teórico. In: BRUSCHINI, C.; HOLLANDA, H. B. (Orgs.). Horizontes plurais: novos estudos de gênero no Brasil. São Paulo: Editora 34 / Fundação Carlos Chagas, 1998. p. 379-409.

DEAUX, K.; LAFRANCE, M. Gender. In: GILBERT, D. T; FISKE, S. T; Lindzey, G. (Orgs.). The handbook of social psychology. New York: McGraw-Hill, 1998. p. 788-827.

FOUCAULT, M. História da sexualidade III - o cuidado de si. Rio de Janeiro: Graal, 1985. 
FRANCHETTO, B.; CAVALCANTI, M. L. V. C.; HEILBORN, M. L. Antropologia e feminismo. In: FRANCHETTO, B.; CAVALCANTI, M. L. V. C.; HEILBORN, M. L. (Orgs.). Perspectivas antropológicas da mulher. Rio de Janeiro: Zahar, 1980. p. $11-43$.

FUNCK, S. B. Descolonizando a sexualidade feminina: as marionetes e as vampiras de Angela Carter. In: GAZZOLA, A. L.; DUARTE, C. L.; ALMEIDA, S. G. (Orgs.), Gênero e representação em literaturas de língua inglesa, v. 4. Belo Horizonte: UFMG, 2002. pp. 45-51.

GLOBO. Corpo: Artigo Indefinido. Caderno Globo 12. São Paulo: Globo Universidade, 2017.

GOMES, N. L. Corpo e cabelo como ícones de construção da beleza e da identidade negra nos salões étnicos de Belo Horizonte. Tese de doutorado. São Paulo: Universidade de São Paulo, 2002.

GROSSI, M. P.; HEILBORN, M. L.; RIAL, C. Ponto de vista: entrevista com Joan Wallach Scott. Estudos Feministas, v. 6, n. 1, p. 114-124, 1998.

HERDT, G. Third sex, third gender: beyond sexual dimorphism in culture and history. Nova Iorque: Zone Books, 1996.

HIJUELOS, O. Yoani Sánchez. Time [online], 30 abr. 2009.

HITA, M. G. Gênero, ação e sistema: a reinvenção dos sujeitos. Lua Nova, v. 43, p. 109-131, 1998.

JESUS, J. G. \& ALVES, H. Feminismo transgênero e movimentos de mulheres transexuais. Cronos, v. 11, n. 2, p, 8-19, 2010.

JESUS, J. G. Gênero sem essencialismo: feminismo transgênero como crítica do sexo. Universitas Humanística, n. 78, p. 241-257, 2014a.

JESUS, J. G. Homofobia: identificar e prevenir. Rio de Janeiro: Metanoia, 2015.

JESUS, J. G. O conceito de heterocentrismo: um conjunto de crenças enviesadas e sua permanência. Psico-USF, v. 18, n. 3, p. 363-372, 2013 b.

JESUS, J. G. Orientações sobre identidade de gênero: conceitos e termos. Goiânia: UFG Sertão, 2012. Disponível em https://www.sertao.ufg.br/n/42117orientacoes-sobre-identidade-de-genero-conceitos-e-termos

JESUS, J. G. Prolegômenos para o futuro pensamento transfeminista. In: Minella, L. S., Assis, G. O. \& Funck, S. B. (Orgs.). Políticas e fronteiras: desafios feministas. Tubarão: Copyart, 2014c. p. 97-111.

JESUS, J. G. Psicologia das massas: contexto e desafios brasileiros. Psicologia \& Sociedade, v. 25, n. 3, p. 493-503, $2013 \mathrm{a}$.

JESUS, J. G. Transfeminismo: teorias e práticas. Rio de Janeiro: Metanoia, 2014b. 
KOFES, S. Categorias analítica e empírica: gênero e mulher - disjunções, conjunções e mediações. Cadernos Pagu, 1, p. 19-30, 1993.

LAQUER, T. Inventando o sexo: corpo e gênero dos gregos a Freud. Rio de Janeiro: Relume Dumará, 2001.

LAURETIS, T. A tecnologia do gênero. In: Hollanda, H. B. (Org.). Tendências e impasses: o feminino como crítica da cultura. Rio de Janeiro: Rocco, 1994. p. 206242.

LOURO, G. L. Gênero, sexualidade e educação: uma perspectiva pós-estruturalista. Petrópolis: Vozes, 1998.

LOURO, G. L. Pedagogias da sexualidade. In: Louro, G. L. (Org.). O corpo educado: pedagogias da sexualidade. Belo Horizonte: Autêntica, 2000. p. 7-34.

LUCON, N. Ariadna incomoda porque existe. A Capa, 9 janeiro 2012. Disponível em http://www.nlucon.com/2012/01/critica-transexual-no-bbb.html

MAUSS, M. Sociologia e antropologia. São Paulo: Cosac Naify, 2011.

MCARTHUR, T. \& MCARTHUR, R. Concise Oxford companion to the english language. Nova Iorque: Oxford University Press, 1998.

MONEY, J. Hermaphroditism, gender and precocity in hyperadrenocorticism: Psychologic findings. Bulletin of the Johns Hopkins Hospital, n. 96, p. 253-264, 1955.

NICHOLSON, L. Interpreting gender. Signs, v. 20, n. 1, p. 79-105, 1994.

OLIVEIRA, P. P. Discursos sobre a masculinidade. Estudos Feministas, v. 6, n. 1, p. 91-111, 1998.

PIERUCCI, A. F. Ciladas da diferença. Tempo Social, v. 2, n. 2, p. 7-33, 1990.

PRADO, C. Quem é Titica, a cantora trans sucesso entre crianças na Angola que estará no Rock in Rio. G1, 22 setembro 2017. Disponível em https://g1.globo.com/musica/rock-in-rio/2017/noticia/quem-e-titica-a-cantora-transsucesso-entre-criancas-na-angola-que-estara-no-rock-in-rio.ghtml

ROTHBLATT, M. The apartheid of sex: a manifesto on the freedom of gender. New York: Crown Publishers, 1995.

ROUGHGARDEN, J. Evolução do gênero e da sexualidade. Londrina: Planta, 2005.

SANTA’ANNA, D. B. Políticas do corpo. São Paulo: Estação Liberdade, 2003.

SCOTT, J. W. Gender and the politics of history. Nova Iorque: Columbia University Press, 1988.

SCOTT, J. W. Gênero, uma categoria útil de análise histórica. Educação e Realidade, v. 20, n. 2, p. 71-99, 1995. 
SERANO, J. Whipping girl: a transsexual woman on sexism and the scapegoating of femininity. Berkeley: Seal Press, 2007.

VENTURA, Zuenir. A falha de Ronaldo. O Globo, 7 maio 2008.

VERGUEIRO, V. É a natureza quem decide? Reflexões trans* sobre gênero, corpo e (ab)uso de substâncias. In: Jesus, J. G. (Org.). Transfeminismo: teorias e práticas. Rio de Janeiro: Metanoia, 2014. p. 19-41.

Contemporary Feminisms and intersecionality 2.0: A contextualization from Transfeminist thought

Abstract: The process of globalization, accelerated by the New Technologies of Information and Comunication, has passed through cultural frontiers and propitiated changes in the conceptions of gender: both in social relations as in the conceptualization itself about what are men and women. The different feminist strands play a central role in this transformation, using the resources of virtuality to spread discourses that presuppose the interaction of oppressions and the intersectionality of identities as subsidies for the construction of new social practices. As a very new feminist thought-action, Transfeminism incorporates these characteristics into its constitution and diffusion, constituting itself as an example of the multiple applications of feminism in terms of theory and politics. This article aims to compose a synthetic view of contemporary discussions of feminism, based on the internet, by bibliographical review and the presentation of the conceptions of 6 (six) Brazilian transfeminist leaders, collected through social networks and arranged in the form of dialogue.

KEYWoRDS: Feminism; Gender; Culture; Intersectionality; Transfeminism. 